\title{
Changes in Office Visit Use Associated With Electronic Messaging and Telephone Encounters Among Patients With Diabetes in the PCMH
}

David T. Liss, $P b D^{1,2}$

Robert J. Reid, $M D, P b D^{2,3}$

David Grembowski, $P b D^{2,3}$

Carolyn M. Rutter, $\mathrm{PbD}^{2-4}$

Tyler R. Ross, $M A^{2}$

Paul A. Fishman, $P b D^{2,3}$

'Division of General Internal Medicine and Geriatrics, Northwestern University Feinberg School of Medicine, Chicago, Illinois

${ }^{2}$ Group Health Research Institute, Seattle, Washington

${ }^{3}$ Department of Health Services, University of Washington School of Public Health, Seattle, Washington

${ }^{4}$ Department of Biostatistics, University of Washington School of Public Health, Seattle, Washington

AC Annals Journal Club selection; see inside back cover or http://www. annfammed.org/AJC/.

Conflicts of interest: Drs Fishman, Rutter, and Reid and $\mathrm{Mr}$ Ross are employees and Dr Liss is a former employee of Group Health Cooperative. Dr Reid is an employee and sharebolder of Group Health Pbysicians, the medical group affiliated with Group Health Cooperative.

\section{CORRESPONDING AUTHOR}

David T. Liss, PhD

Division of General Internal Medicine and Geriatrics

Northwestern University Feinberg School of Medicine

750 N Lake Shore Dr, 10th Fl

Chicago, IL 60611

david.liss@northwestern.edu

\begin{abstract}
PURPOSE Telephone- and Internet-based communication are increasingly common in primary care, yet there is uncertainty about how these forms of communication affect demand for in-person office visits. We assessed whether use of copay-free secure messaging and telephone encounters was associated with office visit use in a population with diabetes.
\end{abstract}

METHODS We used an interrupted time series design with a patient-quarter unit of analysis. Secondary data from 2008-2011 spanned 3 periods before, during, and after a patient-centered medical home (PCMH) redesign in an integrated health care delivery system. We used linear regression models to estimate proportional changes in the use of primary care office visits associated with proportional increases in secure messaging and telephone encounters.

RESULTS The study included 18,486 adults with diabetes. The mean quarterly number of primary care contacts increased by $28 \%$ between the pre-PCMH baseline and the postimplementation periods, largely driven by increased secure messaging; quarterly office visit use declined by $8 \%$. In adjusted regression analysis, $10 \%$ increases in secure message threads and telephone encounters were associated with increases of $1.25 \%(95 \% \mathrm{Cl}, 1.21 \%-1.29 \%)$ and $2.74 \%(95 \% \mathrm{Cl}, 2.70 \%$ $2.77 \%$ ) in office visits, respectively. In an interaction model, proportional increases in secure messaging and telephone encounters remained associated with increased office visit use for all study periods and patient subpopulations $(P<.001)$.

CONCLUSIONS Before and after a medical home redesign, proportional increases in secure messaging and telephone encounters were associated with additional primary care office visits for individuals with diabetes. Our findings provide evidence on how new forms of patient-clinician communication may affect demand for office visits.

Ann Fam Med 2014;338-343. doi: 10.1370/afm.1642.

\section{INTRODUCTION}

Telephone- and Internet-based communication between patients and clinicians is associated with increased access to care, ${ }^{1,2}$ reduced hospitalizations in the chronically ill, ${ }^{3}$ and improved control of type 2 diabetes and hypertension in care management interventions. ${ }^{4,5}$ Besides offering potential clinical benefits, these care modalities do not require patients to incur the time, effort, or cost of traveling to clinicians' offices, ${ }^{1,2}$ and the asynchronous nature of electronic messaging allows patients and clinicians to initiate communication at any time. ${ }^{6}$

For these and other reasons, leaders in American medicine ${ }^{7-10}$ have recommended that the locus of primary care and chronic care delivery expand beyond traditional office visits to include alternative modes of communication. There is considerable uncertainty, however, about how use of these new care modalities affects demand for traditional office visits. ${ }^{6}$ Although one early study found that telephone encounters were a substitute for follow-up visits at a Veterans Health Administration clinic, ${ }_{1}^{11}$ a Scottish 
trial found that telephone encounters for acute issues delayed-but did not preclude the need for-subsequent clinic visits. ${ }^{12}$ Findings on secure electronic messaging have also varied. While Zhou and colleagues ${ }^{13}$ found that office visit use decreased after introduction of an online portal at Kaiser Permanente Northwest (secure messaging was one of several portal tools), Palen and colleagues $^{14}$ found that portal users at Kaiser Permanente Colorado had more office visits than propensity-matched controls during the year after portal registration.

We contribute to the evidence base in this area by examining how patients' use of primary care office visits is associated with use of secure electronic messaging and telephone encounters in a large health care system that featured these care modalities in a patient-centered medical home $(\mathrm{PCMH})$ redesign. ${ }^{15}$ Our primary objective in this natural experiment was to assess changes in office visit use associated with secure messaging threads and telephone encounters in a population with chronic illness. Our secondary objective was to investigate whether PCMH implementation or selected patient characteristics modify associations under study.

\section{METHODS}

\section{Study Setting}

We investigated the impact of secure messaging and telephone encounters on patients' use of primary care office visits at Group Health, an integrated health plan and care delivery system in the Pacific Northwest. Since launching a secure online patient portal in 2000, Group Health added portal tools and engaged in multiple initiatives that encouraged copay-free secure electronic messaging and telephone encounters (secure electronic messaging began in 2002). ${ }^{16-18}$ Group Health further emphasized these care modalities during a 2007-2008 PCMH prototype redesign at a clinic, ${ }^{19}$ where chronically ill patients had $86 \%$ more secure message threads and $10 \%$ more telephone encounters than patients at other Group Health clinics. ${ }^{20}$

After the prototype redesign, Group Health implemented a systemwide PCMH redesign. ${ }^{19,21}$ Group Health staggered the beginning of the redesign across its 26 clinics from January to April 2009; PCMH implementation at each clinic lasted 1 year, followed by the postimplementation period. Secure messaging and telephone encounters were incorporated within overlapping PCMH redesign efforts to improve access, continuity, and follow-up..$^{15,22}$

\section{Study Design and Population}

We used an interrupted time series design ${ }^{23}$ with a patient-quarter unit of analysis. We included data from January 2008 to December 2011, which encompassed
3 study periods: pre-PCMH baseline (4 quarters), PCMH implementation (4 quarters), and postimplementation (8 quarters). Group Health's institutional review board approved all study protocols.

The study population included adults aged 18 to 75 years who received care at Group Health's 26 clinics and had preexisting diabetes mellitus, based on a previously implemented case definition incorporating diagnostic, pharmacy, and laboratory data (Supplemental Appendix). ${ }^{20}$ We required continuous enrollment at Group Health during the baseline year and the first 2 quarters of PCMH implementation. We excluded patients with preexisting dementia. Individuals were censored from analysis after death, disenrollment from Group Health, or aging out of the 18 to 75 age range.

\section{Measures}

Using previously documented methods, ${ }_{1}^{21}$ we extracted automated data on health service use. Monthly primary care use data were rolled up to quarterly counts of office visits, secure message threads (a "thread" includes an original message between a patient and care team, and all messages in subsequent replies ${ }^{24}$ ), telephone encounters, and total primary care contacts (sum of office visits, secure message threads, and telephone encounters). We defined time-varying morbidity burden using resource utilization band (RUB) variables from Johns Hopkins Adjusted Clinical Groups (ACG) System case mix software. ${ }^{25}$ The Supplemental Appendix presents additional information on data collection and measurement.

\section{Analysis}

We computed descriptive statistics for patient characteristics and primary care use. We then estimated 2 multivariable linear regression models, with logtransformed independent and dependent variables, ${ }_{1}^{26,27}$ which estimated the proportional change in office visits associated with a proportional increase in each independent variable. Patients' log-transformed quarterly office visit count was the dependent variable in both regression models. Before performing log transformation, we added a constant of 1 to quarterly counts of each primary care modality, which ensured transformation of uniformly positive data but did not interfere with desirable statistical properties of the lognormal distribution. ${ }^{28}$

Our first regression model (adjusted model) contained 2 key independent variables_-log-transformed quarterly counts of secure message threads and telephone encounters—and adjusted for covariates. The second regression model (interaction model) adjusted for covariates and investigated potential effect modification through covariate-by-log-count interactions 
for study period and selected patient characteristics (age, sex, morbidity, insurance type, plan generosity, and primary care physician behaviors).

We estimated regression models using generalized estimating equations (GEE) with an autoregressive-1 (AR1) working correlation matrix for these longitudinal data, with robust "sandwich" covariance estimates that were robust to misspecification of withincluster correlation. ${ }^{29} \mathrm{We}$ fit a linear model to log-transformed visits with a normal error structure. Analyses were conducted using Stata, version 12.0 (StataCorp). Further details on regression model specification are presented in the Supplementary Appendix.

\section{RESULTS}

The study population consisted of 18,486 adults with diabetes who were aged 18 to 75 years on the first day of PCMH implementation (Table 1). As would be expected in a diabetic population, $70 \%$ were aged 55 years and older, and $34 \%$ had high or very high morbidity.

In the population overall, use of secure messaging and telephone encounters steadily increased over
Table 1. Patient Characteristics at PCMH Baseline and Primary Care Contacts During the Pre-PCMH Baseline Year

\begin{tabular}{|c|c|c|c|c|}
\hline \multirow[b]{2}{*}{ Characteristic } & \multirow[b]{2}{*}{$\begin{array}{l}\text { Total } \\
\text { No. (\%) }\end{array}$} & \multicolumn{3}{|c|}{$\begin{array}{c}\text { Baseline Year Primary Care Contacts, } \\
\text { Mean (SD), No. }\end{array}$} \\
\hline & & $\begin{array}{c}\text { Secure } \\
\text { Message Threads }\end{array}$ & $\begin{array}{l}\text { Telephone } \\
\text { Encounters }\end{array}$ & $\begin{array}{l}\text { Office } \\
\text { Visits }\end{array}$ \\
\hline Total population & $18,486(100)$ & $3.5(7.1)$ & $6.6(8.2)$ & $3.7(3.7)$ \\
\hline \multicolumn{5}{|l|}{ Age-group } \\
\hline $18-44$ & $1,637(9)$ & $3.5(6.9)$ & $4.9(6.0)$ & $3.5(3.4)$ \\
\hline $45-54$ & $3,944(21)$ & $3.5(6.5)$ & $5.6(7.1)$ & $3.6(3.5)$ \\
\hline $55-64$ & $7,400(40)$ & $3.7(7.5)$ & $6.3(7.8)$ & $3.6(3.9)$ \\
\hline $65-75$ & $5,505(30)$ & $3.4(6.9)$ & $8.2(9.7)$ & $4.0(3.7)$ \\
\hline \multicolumn{5}{|l|}{ Sex } \\
\hline Female & $8,879(48)$ & $3.7(7.7)$ & $7.3(8.8)$ & $4.0(3.7)$ \\
\hline Male & $9,607(52)$ & $3.4(6.5)$ & $6.0(7.6)$ & $3.4(3.7)$ \\
\hline \multicolumn{5}{|c|}{ Morbidity (ACG RUB) } \\
\hline Moderate & $12,073(65)$ & $2.5(4.4)$ & $4.1(4.4)$ & $2.6(2.1)$ \\
\hline High & $3,963(21)$ & $4.8(9.0)$ & $8.4(7.7)$ & $4.9(3.3)$ \\
\hline Very high & $2,450(13)$ & 6.7 (11.7) & $15.7(14.1)$ & $7.4(6.6)$ \\
\hline \multicolumn{5}{|l|}{ Insurance type } \\
\hline Commercial & $11,924(65)$ & $3.5(6.4)$ & $5.4(6.5)$ & $3.4(3.4)$ \\
\hline $\begin{array}{l}\text { Medicaid/state } \\
\text { subsidized }\end{array}$ & $408(2)$ & $2.2(5.4)$ & $5.5(5.9)$ & $3.7(3.2)$ \\
\hline Medicare & $6,154(33)$ & $3.7(8.3)$ & $8.9(10.5)$ & $4.3(4.2)$ \\
\hline
\end{tabular}

\section{Figure 1. Quarterly numbers of primary care contacts between care teams and patients with diabetes during baseline, $\mathrm{PCMH}$ implementation, and postimplementation periods.}

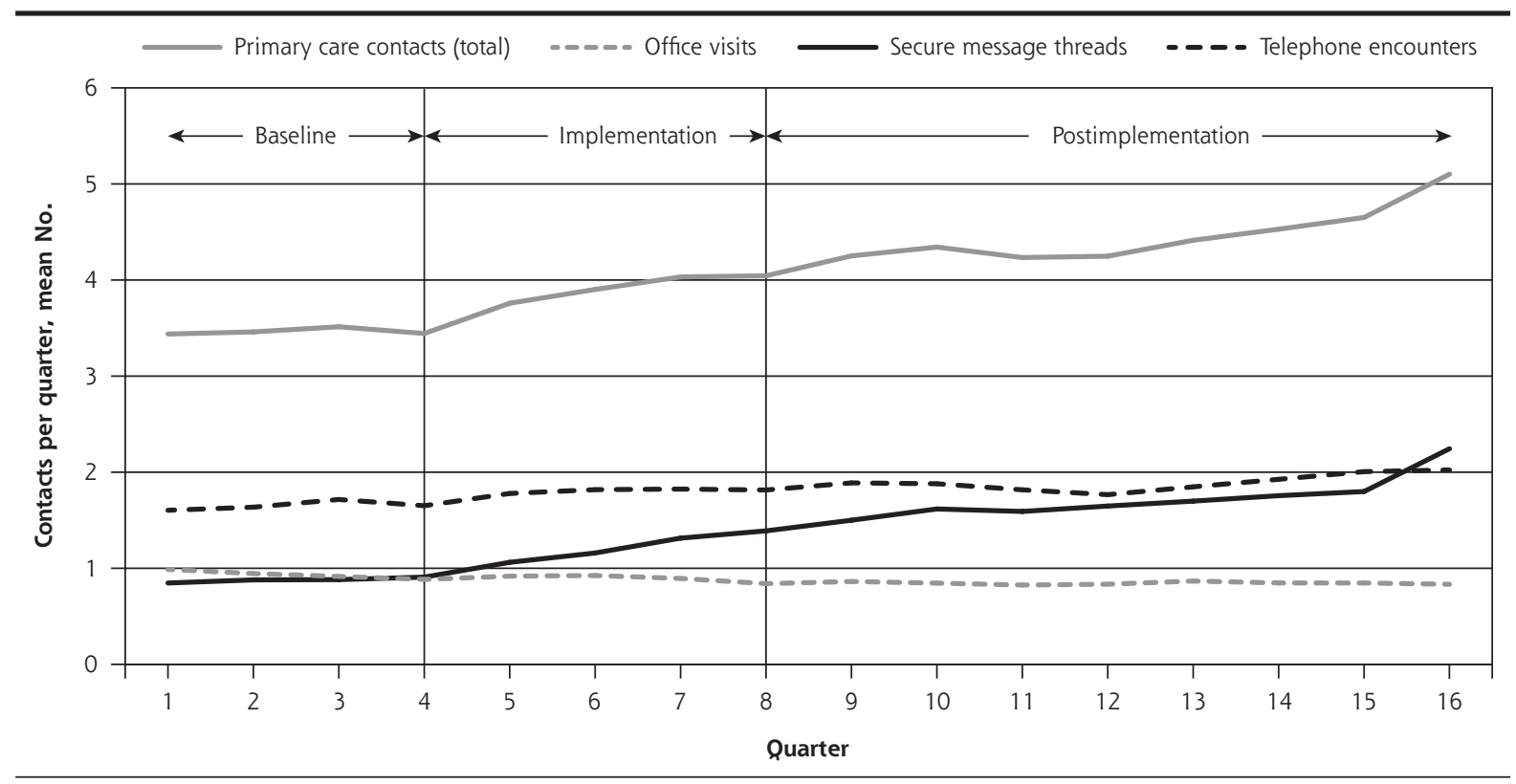

$\mathrm{PCMH}=$ patient-centered medical home . 
implementation and 0.86 (SD 0.89) visits during postimplementation $(8 \%$ total decrease). Largely driven by increased secure messaging, the mean quarterly number of primary care contacts increased from 3.46 (SD $3.48)$ contacts to 3.95 (SD 4.33) and 4.44 (SD 4.68) contacts, respectively (28\% total increase).

In regression analysis, increased use of either secure messaging or telephone encounters was associated with increased office visit use (Table 2). The adjusted model yielded estimates that a $10 \%$ increase in secure message threads was associated with a $1.25 \%$ increase in office visits $(95 \% \mathrm{CI}$, $1.21 \%-1.29 \%$ ), and that a $10 \%$ increase in telephone encounters was associated with a $2.74 \%$ increase in office visits (95\% CI, 2.70\%-2.77\%).

Interaction model results demonstrated some variation across study periods and patient subpopulations, but not to an extent that changed inference (Table 2). The association between log-transformed office visits and telephone encounters decreased over time; using the implementation period as the referent, it was highest during pre-PCMH baseline $(P=.01)$ and decreased further during postimplementation $(P<.001)$. In addition, characteristics such as morbidity and insurance type were associated with statistically significant modifications of main effects. Despite observed interaction effects, linear combinations of coefficients for all study periods and for patient subpopulations in the interaction model were positive at $P<.001$.

\section{DISCUSSION}

In an adult patient population with diabetes, proportional increases in telephone encounters and, to a lesser extent, secure message threads, were associated with proportional increases in primary care office visits. In an interaction model, results varied modestly across selected patient characteristics, and the positive association between log-transformed numbers of office visits and telephone encounters attenuated over time. Although unadjusted office visit use declined by $8 \%$ in the study population, patient-level regression analyses demonstrated that a proportional increase in patients'
Table 2. Changes in Office Visits Associated With Proportional Increases in Secure Message Threads and Telephone Encounters

\begin{tabular}{|c|c|c|}
\hline Model and Variable & $\begin{array}{c}\text { Change With } 10 \% \\
\text { Increase in Secure } \\
\text { Messaging Threads } \\
\%(95 \% \mathrm{Cl})\end{array}$ & $\begin{array}{c}\text { Change With } 10 \% \\
\text { Increase in Telephone } \\
\text { Encounters } \\
\%(95 \% \mathrm{Cl})\end{array}$ \\
\hline \multicolumn{3}{|l|}{ Adjusted model $^{\mathrm{a}}$} \\
\hline Full study population & $1.25(1.21-1.29)$ & $2.74(2.70-2.77)$ \\
\hline \multicolumn{3}{|l|}{ Interaction model ${ }^{\mathrm{a}}$} \\
\hline \multicolumn{3}{|l|}{ Study period } \\
\hline Baseline & $1.13(0.89-1.38)$ & $2.93(2.70-3.15)^{\mathrm{b}}$ \\
\hline PCMH implementation (Ref) & $1.14(0.93-1.35)$ & $2.74(2.55-2.93)$ \\
\hline Postimplementation & $1.20(0.98-1.41)$ & $2.57(2.38-2.77)^{c}$ \\
\hline \multicolumn{3}{|l|}{ Age-group, y } \\
\hline $18-44$ & $1.28(1.03-1.53)$ & $2.93(2.70-3.17)^{\mathrm{b}}$ \\
\hline $45-54$ & $1.21(0.99-1.43)$ & $2.94(2.74-3.14)^{b}$ \\
\hline $55-64$ (Ref) & $1.14(0.93-1.35)$ & $2.74(2.55-2.93)$ \\
\hline $65-75$ & $1.22(0.93-1.50)$ & $2.81(2.56-3.06)$ \\
\hline \multicolumn{3}{|l|}{ Sex } \\
\hline Female (Ref) & $1.14(0.93-1.35)$ & $2.74(2.55-2.93)$ \\
\hline Male & $1.18(0.97-1.39)$ & $2.62(2.43-2.81)^{c}$ \\
\hline \multicolumn{3}{|l|}{ Morbidity burden (ACG RUB) } \\
\hline Moderate (Ref) & $1.14(0.93-1.35)$ & $2.74(2.55-2.93)$ \\
\hline High & $0.84(0.62-1.06)^{c}$ & $2.66(2.46-2.86)^{c}$ \\
\hline Very high & $0.69(0.45-0.93)^{c}$ & $2.72(2.51-2.93)$ \\
\hline \multicolumn{3}{|l|}{ Insurance type } \\
\hline Commercial (Ref) & $1.14(0.93-1.35)$ & $2.74(2.55-2.93)$ \\
\hline Medicaid/state-subsidized & $1.00(0.63-1.38)$ & $3.16(2.83-3.48)^{b}$ \\
\hline Medicare & $0.96(0.68-1.23)$ & $2.78(2.53-3.03)$ \\
\hline
\end{tabular}

ACG = adjusted clinical group; $\mathrm{PCMH}=$ patient-centered medical home; Ref = referent category; RUB $=$ resource utilization band

${ }^{a}$ Adjusted for age, sex, morbidity burden, insurance type, clinician network, well-care waiver, pharmaceutical coverage, education, income, baseline secure messaging use, hemoglobin $A_{1 c}$ level, blood pressure, low-density lipoprotein cholesterol level, study period, calendar quarter, physician secure messaging, and physician telephone encounter use.

b Positive effect modification at $P \leq .05$, compared with referent category.

' Negative effect modification at $P \leq .05$, compared with referent category. 
and physical examinations. ${ }^{1}$ Our observational results, like recent findings from Palen and colleagues, ${ }^{14}$ do not support the hypothesis that, in general, chronically ill patients will use new forms of copay-free communication as an alternative to in-person visits.

This study has several limitations. We did not conduct content analyses of individual primary care contacts, and we did not identify whether a patient or clinician initiated each contact. We could not control for behaviors of nonphysician clinicians, such as medical assistants and nurses, and observed associations cannot be interpreted as causal effects. The study population was limited to individuals with diabetes who were universally insured and of relatively high socioeconomic status, limiting generalizability. Secure electronic messaging and telephone encounters had been conducted at Group Health for several years, facilitating high adoption rates that may be unique to this setting. Group Health's salary-based clinician reimbursement and capitation-based financing probably affected observed care delivery and patterns of use. In addition, although we adjusted for multiple demographic and clinical characteristics, we could not explicitly adjust for patients' propensity to seek medical advice and treatment.

Our findings point to several opportunities for further exploration. Pragmatic trials should assess whether telephone and secure messaging encounters can reduce or delay use of emergency and inpatient services. As primary care is increasingly delivered by clinician teams that communicate with patients outside traditional office visit settings, new definitions of primary care use-and accompanying new payment modelsare needed to encapsulate and reward patient-centered care delivery.

In conclusion, we found that use of secure electronic messaging and use of telephone encounters were associated with additional primary care office visits among individuals with diabetes in a PCMH redesign. Our findings provide evidence on how new forms of patient-clinician communication may affect demand for office visits.

To read or post commentaries in response to this article, see it online at http://www.annfammed.org/content/12/4/338.

Key words: primary care; electronic mail; telephone; communication; office visits; family practice; health services needs and demand; practice redesign; utilization; practice-based research

Submitted July 17, 2013; submitted, revised, December 18, 2013; accepted January 29, 2014.

Funding support: Funding was provided by the National Center for Advancing Translational Sciences (TL1 RR025016), the Agency for Healthcare Research and Quality (R18 HS019129), and Group Health Cooperative.
Previous presentation: Preliminary findings were presented at the Clinical and Translational Sciences Predoctoral Programs Meeting in Rochester, Minnesota, May 8, 2012.

Acknowledgments: Clarissa Hsu, PhD, DeAnn Cromp, MPH, Kelly Ehrlich, MS, and Eric Johnson, MA, assisted with analysis planning and manuscript preparation. Dean Roehl, MD, and Deborah Brown, RN, shared information about protocols in the medical home redesign and clinician experiences at Group Health. James Ralston, MD, provided helpful feedback on an early draft. We thank Claire Trescott, MD, and Michael Erikson, MSW, for their leadership during the medical home redesign at Group Health.

Supplementary materials: Available at http://www.AnnFamMed. org/content/12/4/338/suppl/DC1/

\section{References}

1. Car J, Sheikh A. Email consultations in health care: 1-scope and effectiveness. BMJ. 2004;329(7463):435-438.

2. Car J, Sheikh A. Telephone consultations. BMJ. 2003;326(7396): 966-969.

3. Brown RS, Peikes D, Peterson G, Schore J, Razafindrakoto CM. Six features of Medicare coordinated care demonstration programs that cut hospital admissions of high-risk patients. Health Aff (Millwood). 2012;31(6):1156-1166.

4. Green BB, Cook AJ, Ralston JD, et al. Effectiveness of home blood pressure monitoring, Web communication, and pharmacist care on hypertension control: a randomized controlled trial. JAMA. 2008;299(24):2857-2867.

5. Ralston JD, Hirsch IB, Hoath J, Mullen M, Cheadle A, Goldberg HI. Web-based collaborative care for type 2 diabetes: a pilot randomized trial. Diabetes Care. 2009;32(2):234-239.

6. McGeady D, Kujala J, Ilvonen K. The impact of patient-physician web messaging on healthcare service provision. Int J Med Inform. 2008;77(1):17-23.

7. Margolius D, Bodenheimer T. Transforming primary care: from past practice to the practice of the future. Health Aff (Millwood). 2010;29(5):779-784.

8. Committee on Quality of Health Care in America. Crossing the Quality Chasm: A New Health System for the Twenty-First Century. Washington, DC: Institute of Medicine; 2001.

9. Bates DW, Wells $S$. Personal health records and health care utilization. JAMA. 2012;308(19):2034-2036.

10. Wagner EH, Coleman K, Reid RJ, Phillips K, Abrams MK, Sugarman $J R$. The changes involved in patient-centered medical home transformation. Prim Care. 2012;39(2):241-259.

11. Wasson J, Gaudette C, Whaley F, Sauvigne A, Baribeau P, Welch HG. Telephone care as a substitute for routine clinic follow-up. JAMA. 1992;267(13):1788-1793.

12. McKinstry B, Walker J, Campbell C, Heaney D, Wyke S. Telephone consultations to manage requests for same-day appointments: a randomised controlled trial in two practices. Br J Gen Pract. 2002;52(477):306-310.

13. Zhou YY, Garrido T, Chin HL, Wiesenthal AM, Liang LL. Patient access to an electronic health record with secure messaging: impact on primary care utilization. Am J Manag Care. 2007;13(7):418-424.

14. Palen TE, Ross C, Powers JD, Xu S. Association of online patient access to clinicians and medical records with use of clinical services. JAMA. 2012;308(19):2012-2019.

15. Hsu C, Coleman K, Ross TR, et al. Spreading a patient-centered medical home redesign: a case study. J Ambul Care Manage. 2012; 35(2):99-108. 
16. Ralston JD, Coleman K, Reid RJ, Handley MR, Larson EB. Patient experience should be part of meaningful-use criteria. Health Aff (Millwood). 2010;29(4):607-613.

17. Ralston JD, Carrell D, Reid R, Anderson M, Moran M, Hereford J. Patient web services integrated with a shared medical record: patient use and satisfaction. J Am Med Inform Assoc. 2007;14(6):798-806.

18. Ralston JD, Martin DP, Anderson ML, et al. Group Health Cooperative's transformation toward patient-centered access. Med Care Res Rev. 2009;66(6):703-724.

19. Reid RJ, Coleman K, Johnson EA, et al. The Group Health medical home at year two: cost savings, higher patient satisfaction, and less burnout for providers. Health Aff (Millwood). 2010;29(5):835-843.

20. Liss DT, Fishman PA, Rutter CM, et al. Outcomes among chronically ill adults in a medical home prototype. Am J Manag Care. 2013;19(10):e348-e358.

21. Reid RJ, Fishman PA, Yu O, et al. Patient-centered medical home demonstration: a prospective, quasi-experimental, before and after evaluation. Am J Manag Care. 2009;15(9):e71-e87.

22. Reid RJ, Larson EB. Improvement happens: doctors talk about the medical home. An interview with Charles Mayer, MD, MPH and Eric Seaver, MD. J Gen Intern Med. 2012;27(7):871-875.
23. Shadish WR, Cook TD, Campbell DT. Experimental and QuasiExperimental Designs for Generalized Causal Inference. Boston, MA: Houghton Mifflin; 2002.

24. Carrell D, Ralston J. Messages, strands and threads: measuring use of electronic patient-provider messaging. AMIA Annu Symp Proc. 2005:913.

25. The Johns Hopkins ACG System: Technical Reference Guide, Version 10.0. Baltimore, MD: Johns Hopkins University; 2011.

26. McFadden D. Constant elasticity of substitution production functions. Rev Econ Stud. 1963;30(2):73-83

27. Gujarati DN. Essentials of Econometrics. 3rd ed. New York, NY: McGraw-Hill/Irwin; 2006.

28. Duan N. Smearing estimate: a nonparametric retransformation method. J Am Stat Assoc. 1983;78(383):605-610.

29. Diggle P, Heagerty P, Liang K, Zeger S. Analysis of Longitudinal Data. 2nd ed. Norfolk, United Kingdom: Oxford University Press; 2002.

30. Executive summary: Standards of medical care in diabetes-2013. Diabetes Care. 2013;36(Suppl 1):S4-S10.

\section{CHANGE-OF-ADDRESS FORM FAMILY MEDICINE}

Please complete this form and mail to the following address or fax to Annals Circulation at 913-906-6080:

Annals of Family Medicine, Circulation Department, 11400 Tomahawk Creek Pkwy, Leawood, KS 66211-2680

Check if member of sponsoring organization:

$\begin{array}{ll}\square \text { AAFP } & \square \text { ABFM } \square \text { STFM } \square \text { ADFM } \\ \square \text { AFMRD } & \square \text { NAPCRG } \square \text { CFPC }\end{array}$

ID number from label on your journal cover

OLD Information (Please print.)

\begin{tabular}{lc}
\hline Name \\
\hline Company (if applicable) \\
\hline Address (Street plus Apt or Ste) \\
\hline City \\
\hline Country \\
\hline Telephone \\
\hline E-Mail & Faxtal Code (9-digit ZIP for US) \\
\hline
\end{tabular}

NEW Information (Please print.)

\begin{tabular}{lc}
\hline Name \\
\hline Company (if applicable) \\
\hline Address (Street plus Apt or Ste) \\
\hline City & \\
\hline Country & Postal Code (9-digit ZIP for US) \\
\hline Telephone & Fax \\
\hline E-Mail &
\end{tabular}

